\title{
RANCANG BANGUN APLIKASI PEMETAAN GEDUNG UNIVERSITAS PALANGKA RAYA PADA SUB. BAG BARANG MILIK NEGARA (BMN) BUK UNIVERSITAS PALANGKA RAYA
}

\author{
Viktor Handrianus Pranatawijaya ${ }^{\text {a,1,*}}$, Putu Bagus Adidyana Anugrah Putra ${ }^{\text {b,2 }}$, Adonis Jethro Patianom ${ }^{c, 3}$ \\ ${ }^{a}$ Universitas Palangka Raya, Jl. H. Timang \\ ${ }^{\mathrm{b}}$ Universitas Palangka Raya, Jl. H. Timang \\ ${ }^{c}$ Universitas Palangka Raya, Jl. H. Timang \\ 1 viktor_hp@yahoo.com*; ${ }^{2}$ putu.upr@gmail.com; ${ }^{3}$ adonispatianom@mhs.it.upr.ac.id \\ * corresponding author
}

\section{ARTICLE INFO}

\section{Keywords}

Waterfall

DFD

PHP

Black Box

The State Property Section $(\mathrm{BMN})$

\section{ABSTRACT}

Sub. The State Property Section (BMN) of Palangka Raya University still uses a system that is considered less effective and efficient. Data on buildings, rooms, goods and vehicles belonging to the state which are still stored in the form of excel reports, which can be lost may be lost and if the data has been stored on a computer it does not support the ease of data processing to be used and printed on a report. The research design consisted of three stages: (1) data collection and analysis carried out by means of literature study and observation, (2) applying the modified waterfall method with stages of system analysis, (3) modeling of business processes using DFD, and interface, (4) implementation uses PHP and Mysql as a database to store data. Furthermore, at the testing stage this application uses the Black Box method. The results of the study are a mapping application of Palangka Raya University building on Sub. BMN University of Palangka Raya.

\section{Pendahuluan}

Peran Sistem Informasi pada Universitas Palangka Raya sangatlah penting. Terutama untuk menunjang Universitas tersebut agar lebih maju dan berkembang. Sistem yang bagus dan didukung oleh fasilitas dan SDM yang mumpuni akan sangat membantu dalam kinerja sistem. Pemanfaatan komputer yang tepat dalam pendukung majunya Universitas yang didukung oleh SDM yang handal serta fasilitas lain yang cukup akan dapat mempermudah pengguna untuk menyelesaikan pekerjaan dalam skala kecil atau besar.

Aplikasi atau program yang tepat tentunya akan sangat membantu dalam kelancaran atau kecepatan penyelesaian berbagai pekerjaan apapun. Kantor Sub. Bag BMN BUK Universitas Palangka Raya merupakan kantor yang bergerak di bidang Pengadaan Barang. Gedung Rektorat Universitas Palangka Raya Sub. Bagian BMN BUK memerlukan suatu fasilitas berupa sebuah aplikasi untuk mengetahui sebuah informasi Gedung, Ruangan, Barang dan Kendaraan di setiap Fakultas.

Sub. Bagian BMN BUK Universitas Palangka Raya masih menggunakan sistem yang di anggap kurang efektif dan efisien. Data Gedung, Ruangan, Barang dan Kendaraan yang masih disimpan dalam bentuk laporan excel, yang bias saja kemungkinan dapat hilang dan apabila data tersebut telah disimpan dalam computer hal itu tidak menunjang kemudahan pengolahan data untuk dapat digunakan dan dicetak pada sebuah laporan. Hal ini dikarenakan data yang disimpan bukan pada database yang dapat diupdate sewaktu-waktu, sehingga sering terjadi ketidak cocokan antara data awal dan data akhir. Berdasarkan latar belakang di atas, penulis mengangkat judul penelitian 
Rancang Bangun Aplikasi Pemetaan Gedung Universita Palangka Raya Pada Sub. Bagian BMN BUK Universitas Palangka Raya

\subsection{Landasan Teori}

a. Website

Yuhefizar, dkk (2011:2) menyatakan website adalah keseluruhan halaman- halaman web yang terdapat dalam sebuah domain yang mengandung informasi. Sebuah website biasanya dibangun atas banyak halaman web yang saling berhubungan. Hubungan antara satu halaman web dengan web lainnya disebut dengan hyperlink, sedang kanteks yang dijadikan media penghubung disebut hypertext.

Domain adalah nama unik yang dimiliki oleh sebuah institusi sehingga biasanya diakses melalui internet, misalnya lintau.com, yahoo.com, goggle.com dan lain-lain. Untuk mendapat sebuah domain harus melakukan register pada register-register yang ditentukan. Istilah lain yang sering ditemui sehubungan dengan website adalah homepage. Homepage adalah halaman awal sebuah domain. Misalnya, membuka website www.lintau.com, halaman pertama yang muncul disebut homepage jika mengklik menu-menu yang ada dan meloncat kelokasi yang lainnya disebut web page sedangkan keseluruhan isi/konten domain disebut website.

\section{b. Data Flow Diagram (DFD)}

Analisis perancangan Website Sistem Informasi Praktikum Jurusan Teknik Informatika Universitas Palangka Raya didefinisikan dengan menggunakan DFD (Data Flow Diagram). Semua aliran data yang masuk dan keluar melalui sistem digambarkan dengan DFD, sehingga dapat dilihat dengan jelas aliran data apa saja yang terlibat dalam proses di sistem ini.

Saputra dan Agustin (2012:28) Data Flow Diagram atau yang disingkat DFD merupakan diagram yang menggambarkan alir data dalam suatu entitas ke sistem atau sistem ke entitas. DFD juga dapat diartikan sebagai teknik grafis yang menggambarkan alir data dan transformasi yang digunakan sebagai perjalanan data dari input atau masukan menuju keluaran atau output.

\section{c. Entity Relationship Diagram (ERD)}

Menurut Harsiti (2012:26) Entity Relationship Diagram (ERD) adalah diagram yang menghubungkan antar entitas di dalam penyusunan/perancangan basis data. Diagram Entitiy Relationaship ini ditemukan oleh Chen tahun 1976. Tujuan dari Entity Relationship Diagram adalah untuk menunjukkan objek data dan relationship yang ada pada objek tersebut.Berikut komponen ERD :

- Entitas

Entitas merupakan individu yang mewakili sesuatu yang nyata dan dapat dibedakan dari sesuatu yang lain. Entitas bisa berupa orang, kejadian, atau benda dimana data akan dikumpulkan.

- Atribut

Setiap entitas pasti memiliki atribut yang mendeskripsikan karakteristik dari entitas tersebut. Berikut adalah syarat atribut suatu entitas :

a) Informasi yang diambil tentang sebuah entitas

b) Nama atribut harus merupakan kata benda

c) Kadang nama entitas diletakkan di depan nama atribut untuk ketelitian.

- Relationship

Relasi menunjukan adanya hubungan diantara sejumlah entitas yang berasal dari himpunan entitas yang berbeda. Entitas pertama dalam relationship disebut entitas induk, entitas kedua disebut sebagai entitas anak. Relationship harus mempunyai nama yang berupa kata kerja.

- Kardinalitas 
Kardinalitas relasi menunjukan jumlah maksimum entitas yang dapat berelasi dengan entitas yang lain.

\section{d. Flowchart}

Flowchart adalah penyajian yang sistematis tentang proses dan logika dari kegiatan penanganan informasi atau penggambaran secara grafik dari langkah-langkah dan urut-urutan prosedur dari suatu program. Flowchart menolong analis dan programmer untuk memecahkan masalah ke dalam segmen-segmen yang lebih kecil dan menolong dalam menganalisis alternatifalternatif lain dalam pengoperasian. System flowchart adalah urutan proses dalam system dengan menunjukkan alat media input, output serta jenis media penyimpanan dalam proses pengolahan data.

\section{Metode Penelitian}

Model yang digunakanmerupakansuatuhasildarisiklushiduppengembanganperangkatlunak Model Waterfall (Royce, 1970) yang dibuat oleh Royce pada tahun 1970. Pada perkembangannya banyak bermunculan modifikasi-modifikasi dari model tersebut. Sehingga model yang digunakan pada penelitian ini merupakan model model Waterfall yang modifikasi.Berikut ini merupakan beberapa tahapan penelitian, yaitu:

a) Studi Pustaka dan Observasi

Metode ini melakukan studi pustaka terhadap buku, jurnal ilmiah nasional dan internasional sebagai pendukung dalam penelitian. Observasi dilakukan untuk mengambil data-data untuk titik dan berapa besar radius yang diperlukan untuk menandakan suatu ruangan yang nantinya akan dijadikan area untuk mengeluarkan informasi.

b) Analisis Sistem

Proses pencarian kebutuhan difokuskan pada software untuk mengetahui sifat dari website yang akan dibuat, seperti manajemen hak akses pengguna beserta fasilitas-fasilitas yang ada, pemodelan proses bisnis menggunakan Data Flow Diagram (DFD) dan Entity Relationship Diagram (ERD).

c) Desain Sistem

Proses ini digunakan untuk membuat "blueprint" software seperti, perancangan basis data dan perancangan antarmuka (interface).

\section{Hasil Dan Pembahasan}

Proses modeling akan menerjemahkan syarat kebutuhan kesebuah perancangan software yang dapat diperkirakan sebelum dibuat coding. Proses ini terbagi menjadi 2, yaitu analisis dan desain. Pada analisis menggunakan Data Flow Diagram (DFD) serta Entity Relationship Diagram (ERD). Pada desain akan dilakukan desain tabel, desain navigasi mengunakan Sitemap dan desain antarmuka/representasi interface.

\subsection{Data Flow Diagram (DFD)}

a) Diagram Konteks

Diagram Konteks digunakan untuk menggambarkan Aplikasi Pemetaan Gedung Universita Palangka Raya Pada Sub. Bagian BMN BUK Universitas Palangka Raya secara garis besar atau keseluruhan. Diagram Konteks ini dirancang memperhatikan masukan yang dibutuhkan oleh sistem dan keluaran yang dihasilkan oleh sistem. Diagram Konteks data praktikum dapat dilihat pada gambar 4.1 berikut. 


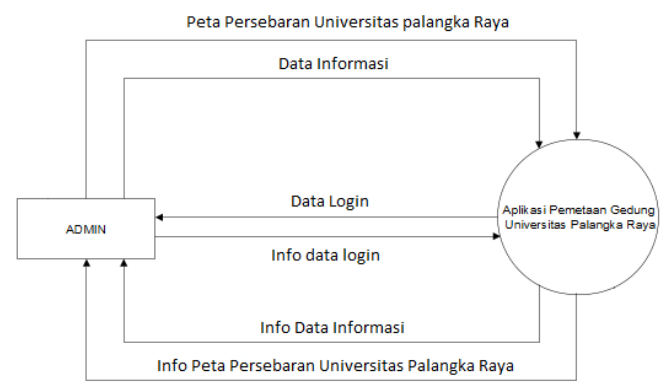

Gambar 4.1 DFD Level 1

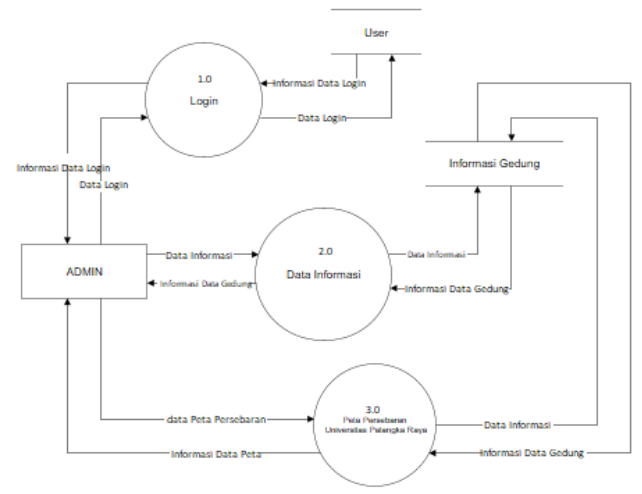

Gambar 4.2 DFD Level 2

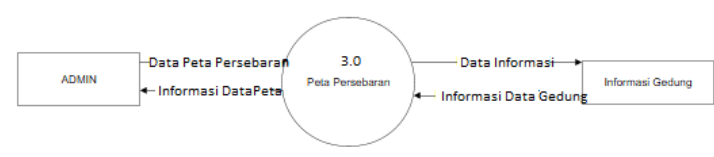

Gambar 4.3 DFD Level 2

\subsection{Desain Database}

Dalam pembuatandatabase sistem informasi arsip surat masuk dan keluar pada kantor perlengkapan rektorat Palangka Raya menggunakan MySQL.

Tabel 4.1 Tabel Users

\begin{tabular}{ccc}
\hline Nama Field & Tipe Data & Ket \\
\hline id_user & int & primary key \\
\hline nama & varchar & \\
\hline username & varchar & \\
\hline password & varchar & \\
\hline level_user & varchar & \\
\hline
\end{tabular}

Tabel 4.1 Tabel Gedung

\begin{tabular}{lll}
\hline Nama Field & Tipe Data & Ket \\
\hline id_gedung & varchar & primary key \\
\hline nama_gedung & varchar & \\
\hline kode_barang & varchar & \\
\hline
\end{tabular}




\begin{tabular}{ll}
\hline tipe & varchar \\
\hline luas & varchar \\
\hline kondisi & varchar \\
\hline lokasi & text \\
\hline kota & varchar \\
\hline provinsi & varchar \\
\hline latitude & varchar \\
\hline longitude & varchar \\
\hline tanggal_perolehan & date \\
\hline jumlah_ruangan & varchar \\
\hline
\end{tabular}

Tabel 4.3 Tabel Ruangan

\begin{tabular}{lll}
\hline Nama Field & Tipe Data & Ket \\
\hline id_ruangan & varchar & primary key \\
\hline id_gedung & varchar & primary key \\
\hline ruangan & varchar & \\
\hline nama_ruangan & varchar & \\
\hline luas & varchar & \\
\hline lokasi & text & \\
\hline photo & blob & \\
\hline
\end{tabular}

\subsection{Desain Interface}

Desain ini menggambarkan rancangan tampilan form menu untuk pembuatan aplikasi pemetaan gedung universitas palangka raya pada sub.bag BMN BUK Universitas Palangka Raya.

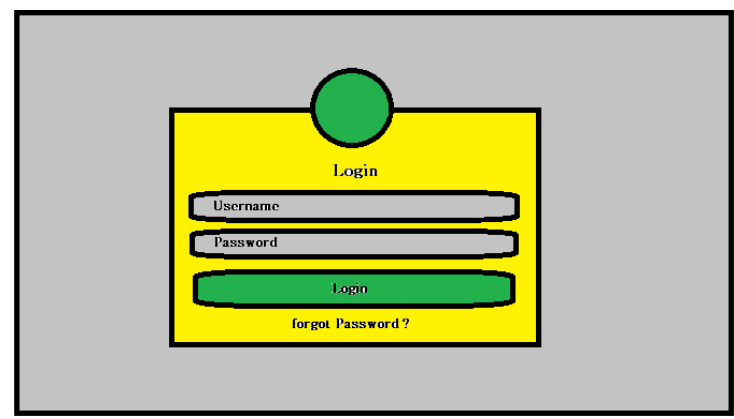

Gambar 4.3 Desain Halaman Login

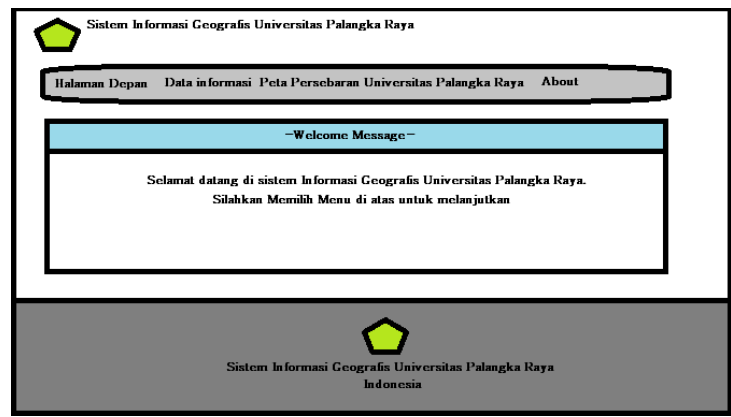

Gambar 4.4 Desain Form Menu Utama

\subsection{Implementasi}

Untuk perancangan antarmuka digunakan dua metode pemrograman, aplikasi server menggunakan Database MySQL dan aplikasi website menggunakan PHP. 


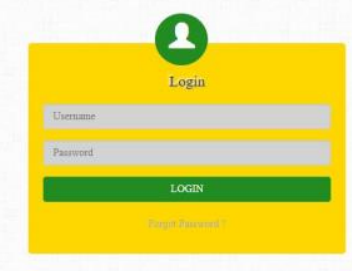

Gambar 4.5 Form Login

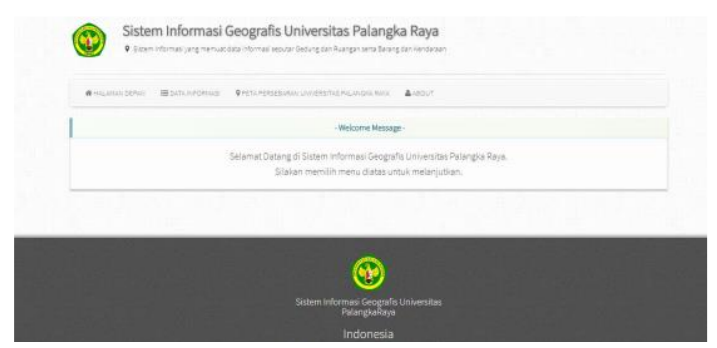

Gambar 4.6 Form Halaman Utama Admin

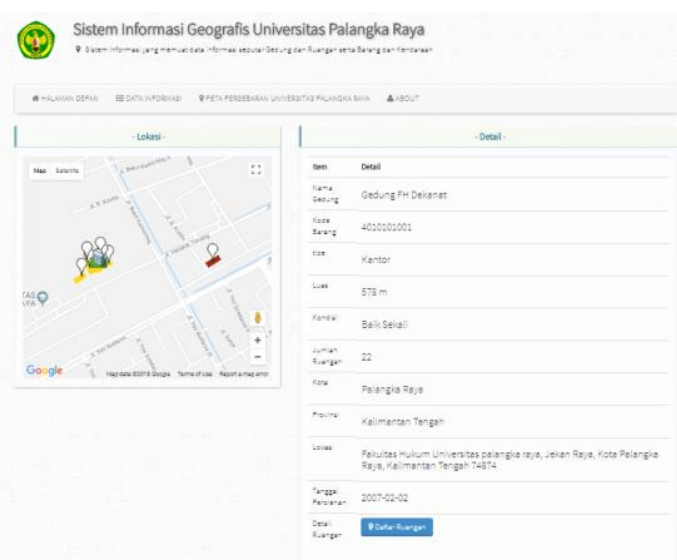

Gambar 4.7 Detail dan Lokasi Gedung

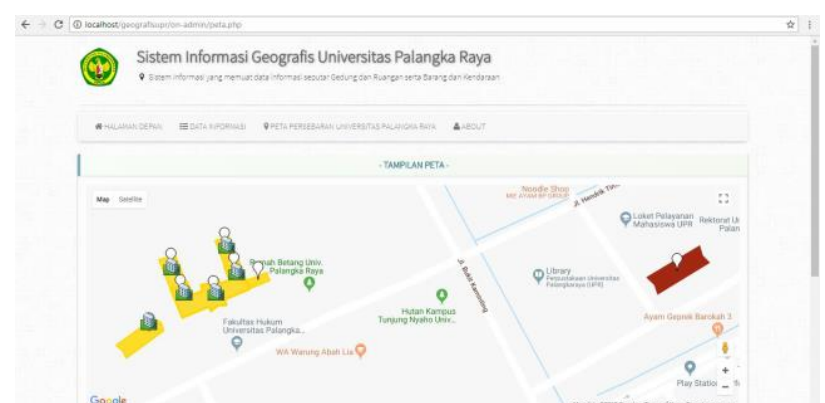

Gambar 4.7 Form Peta Persebaran Universitas Palangka Raya

\subsection{Pengujian}

Pengujian dengan menggunakan metode black box akan mencari kesalahan dengan menjalankan fungsionalitas program satu per satu. 
Tabel 4.4Black Box (Form Login)

\begin{tabular}{clc}
\hline Halaman & \multicolumn{1}{c}{ Proses } & Hasil \\
\hline Login & a. Login tanpa & Ok \\
& username \& & \\
& password (tidak & \\
& dapat masuk) & \\
b. Login tanpa & username (tidak & \\
& dapat masuk) & \\
c. Login tanpa & password(tidak dapat \\
masuk) & \\
d. Login salah & username (tidak \\
& dapat masuk) \\
e. Login salah & password (tidak \\
& dapat masuk) \\
f. Login salah & username \& \\
& password (tidak \\
dapat masuk) & \\
g. Login Username dan & Password Benar \\
(dapat masuk) & \\
&
\end{tabular}

Tabel 4.5Black Box (Form Data Informasi)

\begin{tabular}{|c|c|c|}
\hline Halaman & Proses & Hasil \\
\hline DataInformasi & $\begin{array}{l}\text { h. Menampilkan Data } \\
\text { Table Informasi } \\
\text { Gedung } \\
\text { i. Pencarian Data } \\
\text { Informasi Gedung } \\
\text { (melalui Kata Kunci } \\
\text { di } \\
\text { j. Pencarian) } \\
\text { k. Jumlah data dalam } \\
\text { Table sesuai baris } \\
\text { data batas halaman } \\
\text { 1. Menampilkan Table } \\
\text { selanjutnya } \\
\text { m. } \\
\text { Table seelumnya } \\
\text { n. Tombol Detail dan } \\
\text { Lokasi }\end{array}$ & $\mathrm{Ok}$ \\
\hline
\end{tabular}

\section{Kesimpulan}

Aplikasi ini dikembangkan dengan menggunakan Metode Waterfall yaituRequirements Definition, System and SoftwareDesign, Implementation and UnitTesting, Integration and SystemTesting, dan Operation andMaintenance. Desain sistem yang digunakan yaitu DFD. Selanjutnya pada tahap penulisan Kode program yang digunakan adalah menggunakan Bahasa Pemrograman PHPsebagai desain Interface dan Mysql sebagai database untuk menyimpan data. Selanjutnya pada tahapan testing Aplikasi ini menggunakan metode Black Box. 


\section{JURNAL TEKNOLOGI INFORMASI}

[E-ISSN 2656-0321]

[Vol. 12 No. 2]

Jurnal Keeilmutan dann Aplikasi Bidang Teknik Informaiika

[Agustus 2018]

\section{Daftar Pustaka}

[1] Ceri, Stefano dan Piero Fraternali.2000. Computer Networks: The International Journal of Computer and Telecommunications Networking. New York. North-Holland Publishing Co.

[2] LutfiIndrawan, Muhammad. 2013. Pengenalan dan Instalasi XAMPP. V. InstitutTeknologi Bandung. Bandung.

[3] Pressman, Roger S. 2010. Pendekatan Praktisi Rekayasa Perangkat Lunak Edisi 7. Andi. Yogyakarta.

[4] Rosa A. S dan M. Shalahuddin. 2011. Modul Pembelajaran Rekayasa Perangkat Lunak (Terstruktur dan Berorientasi Objek). Modula. Bandung. 